\title{
Leila Aboulela's The Kindness of Enemies (2015): An Acculturation Approach
}

\begin{abstract}
:
This paper demonstrates a profound analysis to Leila Aboulela's novel The Kindness of Enemies (2015) through the acculturation theory. I exhibit how the acts of prejudice, discrimination, and exclusion of Muslims in the West after the 9/11 attacks have led the Muslim protagonists in Leila Aboulela's work to shift their positive acculturation strategies (i.e. assimilation and integration) to negative ones (i.e. separation and marginalization) as a result of high-level acculturative stress on Muslims. Initially, the paper attempts at presenting the acculturation strategies adopted by each character and the aspirations behind the endorsement of such acculturation strategies. Afterwards, the acculturative stress they encounter due to their Muslim heritage and its negative outcomes on them are manifested in order to highlight their impact on the failure of the initially chosen acculturation strategies by Natasha, Oz, and Malak. Accordingly, the paper illustrates their shift from their primarily followed acculturation strategies to other ones to cope with their sense of marginality and alienation from the dominant society of settlement and to acquire a satisfactory level of adaptation.
\end{abstract}

Keywords: Leila Aboulela, acculturation, discrimination, integration, assimilation, separation, marginalization

\section{Introduction:}

The pillar of this paper is based on one branch of cross-cultural psychology, known as acculturation, which is the process that individuals undergo in response to a changing cultural context (Berry et al. 349). Berry and his colleagues have identified four strategies to be adopted by individuals in acculturation: assimilation, integration, separation, and marginalization. With the variety in personalities and conditions of individuals within a given minority group, the choice of the proper acculturation strategy may vary. Members of a non-dominant group react differently to cultural change. The choice of an acculturation strategy might take place individually by acculturative individuals or collectively by acculturative groups. Some may seek to make cultural and social interaction with the dominant group and do not maintain their original cultural identity, in this case these individuals follow an 'assimilation' strategy. Other members prefer to follow a 'separation' strategy in which individuals hold on to their original culture 
while avoiding interaction with the majority group's culture. The third strategy refers to the case when there is an interest in maintaining both the culture of origin and, simultaneously, a tendency towards interacting with the broader society; this is called an 'integration' strategy. Finally, 'when there is little possibility or interest in cultural maintenance (often for reasons of enforced cultural loss), and little interest in having relations with others [in the dominant society] (often for the reasons of exclusion or discrimination), then the 'marginalization' strategy is defined' (Berry et al. 354-355).

During the long-term adaptation process, individuals are subjected to experience various levels of acculturative stress. Acculturative stress is a response by individuals to life events (that are rooted in intercultural contact), when they exceed the capacity of individuals to deal with them (Berry et al. 362). Stressors range from the experience of prejudice and discrimination to suffering from lack of resources (e.g. education, job opportunities, finances) in the country of settlement. The experience of high-level acculturative stress leads to negative psychological and emotional outcomes on the minority group individuals that should be coped with. The experience of prejudice and discrimination has a significant negative effect on a person's mental health and well-being (Berry et al. 369). Apparently, these outcomes of acculturative stress show the negative influence of acculturative stress on the psychological well-being of the individuals and on the relationship between the minority group individuals and the dominant society.

The acculturation process illustrates the sufferings of the Muslim characters of Leila Aboulela's The Kindness of Enemies as diasporic Muslims in the West after 9/11. This research applies a qualitative approach in literary analysis relying on the acculturation as a critical theory, including acculturation strategies and acculturative stress.

The Kindness of Enemies' contemporary storyline takes place in present-day Britain and Sudan. The main protagonist, Natasha, is a history professor and researcher born in Sudan to a Sudanese father and a Russian mother. Natasha experiences identity conflict and loss throughout the novel due to her consciousness of herself being caught between two dissimilar cultures - her father's Arab Muslim culture and the Western culture of her mother and where she settles. Natasha's interest in researching the life of Imam Shamil, the $19^{\text {th }}$ century Muslim leader who struggled against the expansion of the Russians in Caucasus, drives her to accept the invitation of her bright student, Oz (real name Osama), to visit his house and see Imam Shamil's sword that is kept by his mother, Malak, the descendant of Imam Shamil. Because of a snowstorm, Natasha stays one more night with Malak and Oz. Eventually, in her presence, Oz gets arrested by the police in suspicion of terror-related activities. 
Leila Aboulela's The Kindness of Enemies delves into the meanings of belonging, identity ambivalence and religiosity among Muslims in the West. Aboulela, in this work, depicts the journey of three types of Muslim individuals settling in the West struggling to fit in the mainstream in Britain through adopting different acculturation strategies. However, the rise of Islamophobia after $9 / 11$ puts them under suspicion and social pressure exposing their vulnerability as acculturative individuals. In The Kindness of Enemies, Natasha; Oz; and Malak, develop senses of exclusion and alienation from the dominant society in response to the conflict between Islam and the West. This leads them to change their selected acculturation strategies to other ones in pursuit of peaceful, satisfactory level of adaptation in the society of settlement. Aboulela employs the themes of religiosity and spirituality to show their agency in curing feelings of loss and providing sense of belonging.

In The Kindness of Enemies, Natasha, Malak, and Oz's choices and experiences during their long-term adaptation process as Muslim minorities in Britain are exhibited profoundly; these choices and experiences manifest the acculturation process that the three characters go through. As discussed in the introduction, adaptation refers to the relatively stable changes that take place in an individual or group in response to external demands (Berry et al. 370). Natasha, Malak and Oz's selection of a proper acculturation strategy (Assimilation, integration, separation, or marginalization) is executed individually according to their individual/collective experiences and their individual objectives within their settlement as members of a Muslim minority group in the host society.

Natasha as a hybrid individual, apparently, adopts assimilation as an acculturation strategy for adaptation. In the assimilation acculturation strategy individuals adopt the culture of the dominant group rather than their culture of origin. Although Natasha is a mixed-race individual (half-Sudanese and half-Russian), spending her formative years as a child in Sudan and her Muslim heritage connect her to the Sudanese culture of origin. By moving to Britain and her growing resentment towards her father, she seeks to adopt an acculturation strategy in order to abandon her Sudanese roots as well as her Muslim heritage. Changing her Muslim surname, 'Hussein', to a Western name, 'Wilson' is a symbolic evidence of her determination to ditch her Muslim heritage; and her resentment to her father and abandoning him depict the intentional detachment of her cultural and social connection to Sudan. When her father visits her at university, she is ashamed to be with him and filled with 'impatience to get rid of him'. Moreover, she refuses her father's request to attend her graduation ceremony, preferring the attendance of her 
stepfather, Tony, instead (Aboulela 77). Also, Natasha gives up what she has learnt from Arabic language when she was in Sudan; she notes that her "childhood memory of Arabic had become hazy" and she had communicated with her father in Russian when he visited her (Aboulela 4). Diaz argues that, "language shift and cultural shift have many similarities as large part of the language is culture-specific and an important part of traditional and contemporary cultural expression is lost when the language disappears. Hence, language death is symptomatic of cultural death due to cultural, social, economic and political assimilation " (5). Therefore, Natasha's intentions in diaspora render maximal home culture shedding in acculturation.

On the other hand, obviously, Natasha's attempt to Westernize is her approach for maximal culture learning in the country of settlement. She takes up Western practices that contradict with Islam and the Arab culture. Natasha drinks wine; had a boyfriend and an abortion; moreover, she sometimes organizes Christmas parties. In Berry's elaboration, 'when one's heritage culture no longer contributes to one's sense of self, then exclusive identification with the dominant society can take place, resembling the assimilation acculturation strategy' (359). Accordingly, with Natasha taking procedures and practices that allow her to dissolve in the mainstream culture (host culture learning) in Britain and, simultaneously, separating herself from her homeland culture and religion (home culture shedding), she fulfills her assimilation acculturation strategy.

Unlike Natasha, the experiences and practices of Malak in acculturation deduce that 'integration' is her adopted acculturation strategy. Integration strategy takes place when 'some degree of cultural integrity is maintained, while at the same time members of an ethnocultural group seek to participate as an integral part of the larger social network ' (Berry et al. 354). Malak, as a diasporic woman, maintains a 'heritage identity' as she seems to be proud of her ancestor, Imam Shamil, and her Muslim Caucasian heritage. Preserving iconographies like Imam Shamil's sword and Arabian decorated rugs and cushions are indicators of her persistence in maintaining her culture of heritage. In addition, she attends Muslim Sufi spiritual lessons; apparently, she follows her ancestor Imam Shamil in Sufism, with a modern ideology though — characterized by forgiveness and passivity (Aboulela 8). She moves from London to an isolated farmhouse. Even the nearest town, Brechin, is miles away. This appraisal of privacy and isolation does not necessarily mean that she is not intermingling in the host society. 
Nevertheless, Malak seems adapted well in the country of settlement. She is a successful actress; she 'has a diverse range of accents and trained at the Bristol Old Vic Theatre school' and has been one of Macbeth's witches on stage. Besides acting in several plays on stage she has appeared on TV and played an Iranian ambassador in a Disney cartoon (Aboulela 4). With the extremist Muslim views claiming that being an actress, she is not a good Muslim; she declares: "I couldn't care less what conservative Muslims think of me" (Aboulela 9). Malak believes that she, as a Muslim, has a life full of freedom in the British society; she explains: "We have freedom to practice and teach and bring up our children in our own faith ... When I hear Muslims in the West complaining, I have no sympathy for them" (Aboulela 75). Malak assumes that the society of settlement accepts her ethnic group; she finds that the dominant group holds 'widespread acceptance of the right of all groups to live as culturally different peoples within the same society' (Berry et al. 355). Thus, Malak's integration acculturation strategy is built on her attachment to her heritage and religion on one hand, and her well-adjustment in the host society on the other.

$\mathrm{Oz}$, also, shows a tendency towards following an integration acculturation strategy, like his mother. As referred to before, $\mathrm{Oz}$ is a secondgeneration immigrant, so he suffers from some uncertainty and ambivalence, especially in his understanding of religion. Thus, he seeks an integration strategy to acquire acceptance from both the dominant society and the minority Muslim society he belongs to. In pursuit of acceptance in the British society, Oz decides along with his family, friends and teachers to avoid being called by his real name, Osama - the name 'Osama' would raise a negative comparison with Osama Bin Laden, Al-Qaeda leader during 9/11 terrorist attacks - replacing it with Ossie or, more frequently, Oz. The name change can be interpreted in the acculturation process as 'conflict avoidance' reaction in response to the tension between the West and Islam (Berry et al. 359). Oz appears to be well-adjusted with the dominant culture though. Despite his awareness of distinctiveness from the majority group, $\mathrm{Oz}$ wears fancy clothes like his peers at university; Natasha comments:

He was, I had noticed, proud of his clothes. But then many students nowadays were. They surprised me with their Uggs and Hunter Wellies; their leather jackets and mobile accessories. The markets had them by the throat; they might be in debt, they were surely struggling, but they needed what generations before them had easily done without. (Aboulela 75)

In relevance, Berry et al. indicate that, "education appears as a consistent factor associated with possible adaptations ... education may attune migrants to features of the society into which they settle; it is a kind of pre- 
acculturation to the language, history, values, and norms of the new culture" (366). Oz's well-adjustment with his friends and peer students is evident as he 'liked to make his classmates laugh at his impersonations of politicians' (Aboulela, 7). Also, at his bedroom he hangs posters of American superhero movies, like Spider-Man and X-men Die by the Sword 5 (Aboulela, 75). These features prove Oz's dissolution in the British society; he was born there and studies there, so he perceives well its culture and dissolves well with its members.

On the other hand, $\mathrm{Oz}$ appears to idealize his heritage and religion. $\mathrm{He}$ sees Imam Shamil as an ideal abnormal person; he believes that Imam Shamil does not come to anyone's dreams, only those 'who achieved a certain spiritual level' (Aboulela 14). Oz is also a member of the Muslim Student's Society at university and attends speeches delivered by Muslim speakers there. Besides, he idealizes his religion and this is evident in his wellacknowledged about the Sharia's rules and his adherence to doing the prayers on time. In his attitudes, he shows neither hostility towards non-Muslims nor any signs of vulnerability to radicalization. Natasha sums up Oz's status by stating: "Oz wasn't lonely, he wasn't depressed or isolated. He didn't seem to me to have more political grievances than average. He wasn't disadvantaged and wasn't estranged from his family ... So I judged Oz to be integrated and well adjusted" (Aboulela 149). In other words, Oz does not have the conflict of 'scarce resources' that encounter some other Muslims in the West and lead them to radicalization. Nevertheless, Oz feels that he is not fully satisfied with himself or his status quo; he states: "I would like to be braver ... to be assertive enough not to mind my name or not to care what others think about my mother's job" (Aboulela 45). Accordingly, Oz adopts an integration acculturation strategy because he seeks acceptance in both the dominant society and the Muslim community he belongs to.

Although Natasha, Malak, and Oz seem well-adjusted in their new adopted society despite their consciousness of distinctiveness from the mainstream in Britain, they are subject to encounter various problems (stressors) that would lead to different levels of acculturative stress during their long-term adaptation processes. As pointed out in the introduction, the acculturation process does not only rely on the individual's choice of the strategy, but also on the degree of acceptance from the dominant society to the chosen acculturation strategy and acculturative individuals. Berry declares that although in pluralistic societies (like the British society) diversity and openness to accept new cultures are common, 'there are wellknown variations in the relative acceptance of specific ethnocultural groups.' Some groups are less accepted; therefore, these groups are subject to 
experience acts of hostility, rejection and discrimination against (Berry et al. 364). Such experiences are referred to as 'stressors' (the negative experience people have to deal with) that take place during long-term adaptation and acculturation process (Berry et al. 362). With the rise of unacceptance and hostility against a minority group, acculturative stress emerges.

In accordance, as Muslim individuals settled in a society that is prone to Islamophobia, Natasha, Malak, and $\mathrm{Oz}$ become subject to experience different shapes of stressors like, discrimination, prejudice and suspicion due to their Muslim heritage. Berry et al. confirm that acculturative stress is experienced with the existence of challenges that create serious threats to the individual's well-being (361). In The Kindness of Enemies, Islamophobia serves as a stressor leading to acculturative stress. Sources of acculturative stress may stem from parents, school, peers, community, and media (Anisa N. Goforth et al. 199). Evidently, the three characters have taken measures to avoid conflict with the dominant group; Natasha and $\mathrm{Oz}$ have changed their surname and first name respectively, while Malak has moved to an isolated farmhouse out of London. These actions are taken to secure the success of the adopted acculturation strategies and to reduce the stressors that might be experienced during the acculturation process. These decisions are viewed as problem-avoidance stress coping strategy during acculturation to control such stressors. However, when the stressors are highly problematic, high level acculturative stress is resulted.

Due to the rise of Islamophobia, especially, by the Western media, $\mathrm{Oz}$ gets arrested as a suspicious extremist after being seen by a neighbor swinging away Shamil's sword at snowmen he made himself. Oz's arrest as a suspicious Muslim extremist is considered a stressor that would lead to a high-level acculturative stress on him as well as other Muslims especially those who are close to him like Malak and Natasha. Following the arrest of $\mathrm{Oz}$, Natasha and Malak encounter other stressors. After being seen at Oz's house within his arrest, Natasha's office and desktop at university is searched by the police; they investigate her about the titles of her papers; her political views, her other nationalities, and of course, her relationship with $\mathrm{Oz}$ (Aboulela 175). Moreover, her mobile phone and laptop are taken by the police while arresting Oz. Natasha perceives these actions as prejudice from the dominant group, as she states: "To have your personal files examined, to reveal what is exceedingly intimate - a password and search engine historyfelt hundred times worse than having luggage examined at the airport" (Aboulela 175). Discrimination, prejudice and racism are identified as the major sources of acculturative stress (Berry et al. 369). In response, Natasha experiences racial hostility from the British authorities after being seen by 
her colleagues in this position. Finding the entrance sealed because of her at university with the eyes of her colleagues filled her with embarrassment (Aboulela 175). Furthermore, within her shock of the arrest of $\mathrm{Oz}$ and the related police interrogation with her, Natasha feels discriminated against in the presence of the policemen investigating her house robbery. She reflects: "On cue, my skin flared in their presence, it became more prominent than what I was saying; and I was now an impostor asking for attention, a troublesome guest taking up space. They had better things to do and worthier citizens to protect" (Aboulela 108). This quote highlights Natasha's feeling of 'otherness' by the society and the authority, as she is not seen by them like any other citizen.

Malak, on the other hand, experiences intense acculturative stress after being suspected to be funding terrorism owing to the money she sends to her relatives in Chechnya (Aboulela 225). Consequently, she is excluded at her work field. Malak explains: "I can see this unraveling. My dinner invitations drying up, even the offers of roles dwindling ever so slowly without knowing exactly why" (Aboulela 226). Accordingly, the scarce of work opportunities, as a result of being an under suspicion Muslim, is another stressor that leads to the production of acculturative stress on Malak. Berry states that the experience of stress during the acculturation process 'can be advantageous (such as providing opportunities and interesting experiences), as well as undermining one's life chances (such as limiting opportunities and diminishing experiences that provide meaning to life)' (362). Obviously, Malak experiences the latter one since her work opportunities are diminishing; and, accordingly, she finds herself unaccepted by the members of her work field. Therefore, she is alienated by the majority group as a result of being a Muslim suspect of an activity - funding terrorism - she is against in the first place. Accordingly, Islamophobia and the policies of Britain against Muslim individuals serve as stressors that impede the flow of the acculturation process sought by $\mathrm{Oz}$, Natasha and Malak leading to the experience of high levels of acculturative stress.

Furthermore, acculturative stress could be experienced collectively among Muslim communities in diaspora in the West as much as individually. This collective experience is depicted perfectly by Aboulela through presenting the contrast and discrimination in the media coverage of the news of $\mathrm{Oz}$ by his arrest and after his release without charges. The arrest of $\mathrm{Oz}$ has been a news item; in the Sunday papers it was a headline with the 'words standing thin on the page like spikes: A twenty-one-year-old man is being held at a high-security area of Glasgow's Govan police station after officers raided a property near Berchin on Thursday. His arrest is understood to be 
related to downloading radical Islamist material (Aboulela 182-183).

Nevertheless, the news of his release 'was nothing among the snow warnings, cancelled flights and delayed trains' (Aboulela 224). This discrepancy in the media coverage arouses collective feelings of discrimination and prejudice among the members of the Muslim community Oz belongs to as much as himself as an individual. Notably, Natasha is the one who makes this comparison of the media coverage of Oz's news; this shows how she shares the same stressors and acculturative stress with other Muslims within the acculturation process in the West. Jaimee Stuart clarifies that, 'the international politicization of Islam and the increased anxiety towards this group has meant that Muslim communities have become the targets of discrimination, prejudice, and negative media coverages' (22). Thus, there is a collective, not merely an individual, awareness among Muslims in the West of discrimination in the media against their Muslim race. This, therefore, acts as a collective stressor that should be dealt with by Muslims in the West during their acculturation process.

In reaction to high level acculturative stress experienced by the three characters, negative psychological and emotional outcomes are produced. Following the arrest of $\mathrm{Oz}$ and the investigations in relation, Natasha commences a complex state-mentally and emotionally. Berry presents the outcome of acculturative stress as 'a particular set of stress behaviors which occurs during acculturation, such as lowered mental health status (specifically confusion, anxiety, depression), feeling of marginality and alienation ... and identity crises' (Comparative Studies 492). Immediately after the arrest of $\mathrm{Oz}$, Natasha is subject to a state of confusion; she is caught in ambivalence between staying with Malak by her side at this difficult moment and fleeing away, telling herself: "it's bad enough that you're already involved; save your skin" (Aboulela 82). Spontaneously, Natasha hurriedly leaves Malak's house without saying anything; her reaction reflects her feeling of fear and anxiety. Natasha states that after the investigations and scrutinization of her office, she cries for the first time since the death of her mother. Moreover, the racist dream she has, in which one of her students calls her 'black' and 'fat', reflects Natasha's mental state then (Aboulela 114). She describes her psychological condition by noting that her dignity is shaken, and her balance has broken (Aboulela 176). Her depression leads her to realize that all her efforts for assimilation have gone in vain; her attempts to fit in the mainstream socio-cultural context have failed: "They sealed the entrance and though my colleagues were restrained in their curiosity, I shrank. Every step climbed, every achievement, every recognition - all that hard work - had not taken me far enough, not truly redeemed me, not landed me on the safest shore" (Aboulela 175). 
Furthermore, her colleagues' reaction towards her after being investigated and the scrutinization of her office has aroused her feelings of alienation and marginality. She is disappointed by the lack of support from her colleagues; 'coolness' between her and them is resulted. She declares that her confidence is shattered even though she still has her job and no formal charges have been leveled against her. She feels marginalized at her work place and in the society; as an outcome of acculturative stress she declares: "It now took me conscious effort to walk with my head held high. My voice became softer, my opinions muted, my actions tentative. I thought before I spoke, became wary of my students and, often, bowed my head down" (Aboulela 324). The acculturative stress she has encountered before the arrest of $\mathrm{Oz}$ is controllable and would be classified as 'advantageous' since it has given her motivation to study and work harder to achieve high standardsand she did. However, since the arrest of $\mathrm{Oz}$ and what follows, the acculturative stress has become unmanageable and out of her control, leading her to negative psychological and emotional outcomes, specifically, alienation and marginalization from the majority group.

Similarly, Malak is engaged in psychological and emotional conflict as an outcome of experiencing a highly problematic acculturative stress. In corollary to the arrest of her son, Oz, Malak's mental health and well-being are negatively affected. Malak, due to her depression resulting from the arrest of $\mathrm{Oz}$, suffers from psychosomatic problems. Heightened psychosomatic symptom level is included by Berry and others as one of the predictable outcomes of acculturative stress (Comparative Studies 492). Natasha notes that 'her [Malak] movements were slow and tentative. She was not herself' (Aboulela 82). When Natasha meets Malak a few days later she adds: "Here movements were a little nervous, her shoulders dropping. Despite the effort over her appearance, she looked the slightest bit gaunt" (Aboulela 186). In addition, Malak also experiences other outcomes of acculturative stress; she perceives that she is alienated and marginalized by the mainstream after the arrest of $\mathrm{Oz}$ and following being suspect herself. The scarcity of acting opportunities and dinner invitations arouses her feelings of detachment from the dominant society. She reacts: "Not much needs to be said, does it? One day you are okay, strong and acceptable and then, just like that, everyone turns their back" (Aboulela 226). Aboulela describes the psychological, emotional and social status of Malak in reaction to acculturative stress by noting:

The wobble added years to her age, a slip-up as if she has been acting all the time, playing the role of a London actor, a glamorous woman of the world and now this was her real self. One of those who don't 
matter, who shuffle down the street, reeking of failure if not trouble, suspect and unwanted. (Aboulela 81)

Accordingly, Malak, before the arrest of Oz, seemed well-adjusted and adapted with the British society, but with the emergence of highly problematic acculturation stress, negative psychological, emotional and psychosomatic effects emerge. Her adopted integration acculturation strategy appears to be unwelcomed by the dominant society leading her to feelings of alienation and marginalization.

Also, Oz, after encountering high level stressors - arrest and suspicion - is negatively affected, psychologically and emotionally, even though he is released without charges. As an outcome to acculturative stress, $\mathrm{Oz}$ declares that he has psyched out for getting arrested and suspected as a terrorist (Aboulela 298). Anisa N. Goforth et al. argue that 'immigrant youth who perceived discrimination against exhibit high levels of acculturative stress, internalizing symptoms (e.g. withdrawal, somatic complaints, anxiety, and depression) and behavioral difficulties, which, in return, lowered levels of life satisfaction and self-esteem' (199). Accordingly, as a secondgeneration immigrant, $\mathrm{Oz}$ is assumed to be highly vulnerable to negative psychological struggles (Anisa et al. 199). In incarceration, Oz has been locked up in a tiny room; couldn't sleep. He has been watched every single minute and anything he said or done is written and reported to superior officers (Aboulela 298). After his release, he hasn't spoken to anybody, even his mother. He locked himself in his room and refused to eat. All these actions are depressive reactions to what he has undergone; he believes he 'shouldn't have been there in the first place' (Aboulela 221).

Roli and her colleagues argue that acculturative stress has been found to reduce adjustment and well-being of immigrant youth (683). This argument justifies Oz's feeling of detachment from the larger society. Therefore, he considers giving up his studies, his whole life in Britain (Aboulela 225). Like Natasha and Malak, Oz perceives that he is alienated from the society in which he grew up and educated in. When one's social identity is fiercely contested by the dominant discourse ... one of the first places we can witness psychological, social, and political fallout is in the lives of young people (Stuart 22). The social identity of $\mathrm{Oz}$ as a diasporic individual, which lies in his religion as a Muslim in the West, makes him prone to arrest, suspicion and discrimination. Stuart adds: "Young people are at risk of maladaptation due to their membership in a social group that is subjected to discrimination" (22). Accordingly, the adopted integration strategy by Oz does not appear to be viable with the existence of Islamophobia in his society of settlement. Thus, it is evident that as an 
outcome of the acculturative stress experienced by three main characters in The Kindness of Enemies, they develop feelings of alienation and marginality from the majority group in response to their Muslim heritage.

In reaction to acculturative stress and its psychological and emotional outcomes, Aboulela's main characters follow coping strategies to manage stress and acquire well-adaptation. Natasha, Malak and $\mathrm{Oz}$ choose from one of the three stress coping strategies endorsed in acculturation: problemfocused coping (attempting to change or solve the problem); emotionfocussed coping (attempting to regulate the emotions associated with the problem); and avoidance-oriented coping (characterized by passivity and patience) (Berry et al. 365). Beginning with Oz, his decisions after going through a highly problematic acculturative stress—being a suspect — reflect his sought stress coping strategy. An immediate decision after his release without charges is to never go back to university and join his father in South Africa (Aboulela 221). This shows his realization that he wouldn't be welcomed at university even though he isn't convicted of any terrorist activities. He thinks that he would be regarded by the professors and colleagues as a threat and a suspect. Thus, going back to university would serve as a stressor on him that he is looking forward to avoiding by not going back; eventually, he decides to join a university in Cardiff. Leaving his university for another one far away from home is considered by $\mathrm{Oz}$ an opportunity to start afresh in a place he would be unknown, released from the history he would be acknowledged with at his home university. Following his educational decision to move to another university, he comments: "I started to think of myself as a student again not a criminal" (Aboulela 299). Therefore, this decision can be considered as an attempt to release himself from the stress he might experience at home. It cannot be identified as a problem-focused coping strategy since stressors like, Islamophobia, prejudice and discrimination would exist and be experienced at the university in Cardiff as the Western culture is there too, so the problem is not solved. However, emotion-focused coping strategy is directed at reducing the level of distress associated with a stressful situation (Kosic, 270). Thus, it can be assumed that by that emotion-focused coping is the strategy he follows since joining a university away from home in a new environment that would reduce his stress.

Malak, in fact, follows two coping strategies, one for a short-time and the other for a longer period. As referred to before, adaptation is a long-term process in which individuals encounter stressors from time to time; theses stressors range from controllable or surmounted stressors to uncontrollable, overwhelming stressors (Berry et al. 364-365). First, the arrest of $\mathrm{Oz}$ is 
considered a stressor to Malak that produces an immediate depressive reaction. Eventually, after absorbing the shock of his arrest, Malak adopts a problem-focused strategy in order to find a solution to her son's trouble. She states: "I was in denial when he was first arrested. Then I told myself I have to help him in every way, every possible way" (Aboulela 186). Malak has coped positively with the stressor (the arrest of $\mathrm{Oz}$ ) by launching a campaign demanding his release. Relatively, Berry et al. assume that when acculturative problems (stressors) do arise, but have been successfully coped with, stress will be similarly low and immediate effects positive (365). The release of $\mathrm{Oz}$ afterwards is the positive outcome to her coping strategy even if her campaign is not the main reason for his release. But this stressor is identified as a controllable one since there is a way to solve the problem.

Nevertheless, by the encounter of unmanageable stressors, such as being suspected to fund terrorism and becoming marginalized by members of her work field, the problem-focused strategy is not viable. Instead, she turns to an emotion-focused coping strategy through the agency of spirituality and religiosity. By her realization that she is alienated by the dominant community of settlement, Malak seeks reducing her sense of stress and depression since the situation is out of her capability to solve. Malak utilizes her religiosity and spirituality as her means to cope with acculturative stress and its negative psychological and emotional outcomes. Zeenah Adam points out that, "meta-analysis on religion and mental health indicate that increased religiousness predicts better adjustment and faster recovery from depression, anxiety and traumatic loss" (10). Malak, in return, goes to a $\mathrm{zikr}^{1}$ gathering in reaction to her depression and anxiety. At the end of the Zikr session, 'Malak looked as if a load had been lifted from her shoulders. The darkness under her eyes was gone' (Aboulela 230). This coping through spirituality is one of the adaptive coping techniques known as 'religious coping'. Religious coping, according to Adam, is defined as 'the use of cognitive-behavioral techniques to manage stressful situations in light of one's spirituality or religious beliefs' (11). Religious coping buffers the negative effects of stress on well-being (Adam 13). In comparison with the definition and objectives of the emotionfocused coping strategy, one can extract that religious coping shares the same objective of emotion-focused strategy - reducing and managing stress.

Malak, afterwards, practices religious coping permanently within the longterm adaptation process. Also, in reaction to the acculturative stress she encounters, Malak sets off a spiritual journey to spiritual places, where she would sense the powerful presence of "Allah". Malak reflects: "I don't want anyone to hear me. The trees, the wind, the angels. That's enough for me.

\footnotetext{
${ }^{1}$ A Sufi ritual consisting of the repetition of words in praise of god.
} 
Sometimes, I can't bear to talk to people, Natasha. Not after what happened to Oz. I can't be the same again ... I went through days when I didn't want to talk to anyone at all" (Aboulela 327). Therefore, Malak's spiritual journey is her approach to cure herself from depression and anxiety. She also seeks religious coping as a result to her feeling of alienation and marginalization. In conclusion, Malak pursues emotion-focused coping strategy through the agency of religion and spirituality to overcome the outcomes of acculturative stress.

Natasha, through her coping strategy, does not only strive to overcome acculturative stress or to cope with stressors, she also seeks belonging and connection to home as a diasporic individual. Natasha also follows an emotion-focused coping strategy but in two phases. The first phase of her coping strategy lies in her visit to Sudan. While the second and final phase takes place by her return to Britain.

Natasha's life is a nomadic one in which she works hard to fit in and cure her sense of loss. She wants to fit in Sudan but failed, then she moved with her mother to Britain and strives to belong, but by the arrest of $\mathrm{Oz}$ she develops feelings of alienation and marginalization. Having experienced these negative feelings, she urgently returns to her birthplace, Sudan, to visit her sick father upon his request. Her return to Sudan is an opportunity to move away from the acculturative stress she experiences in Britain as well as an opportunity return to her roots and redefine her identity. By her arrival to Sudan, her father has passed away already. Despite the resentment she holds against him since leaving Sudan, she expressed her regret for not meeting and talking to him before his death to reconcile her sense of loss: "I had wanted to see him again. It was true. I wanted to argue with him and listen to him rant" (Aboulela 259). However, the sense of connection she has been yearning to feel in the presence of her father is acquired through meeting her brother, Mekki. The connection she finds with Mekki stems from the common features they share from their father. She explains: "I looked at his forehead that was like mine ... I knew, instinctively, before he even spoke that his mind was like my mind and that we both, mentally, introspectively, like our father" (Aboulela 263). Thus, she perceives the feeling of family through meeting with Mekki, stating that 'this connection was enough for me' (Aboulela 263).

Besides the warm feeling of family with Mekki, Natasha spends her time in Sudan in mode of reminiscence. She meets her Russian childhood friends who are still in Sudan. She becomes overwhelmed by her father's room and library. She looks for Tony's (her stepfather) old house in Sudan 
and roams in it to relive the old days. At Tony's house she recognizes feeling of homesickness. She arouses 'yearning for an identifiable place where she could belong' (Aboulela 302). Without experiencing acculturative stress in Britain and feeling alienated and marginalized there, her return to Sudan wouldn't have aroused in her these themes of nostalgia and homesickness. Natasha's return to Sudan, meeting with her brother, and this state of reminiscence serve as alleviators to her stress as well as her perpetual sense of loss.

The second phase in Natasha's emotion-focused coping takes place as she joins Malak in her spiritual journey. In a recap to her visit to Sudan, Natasha notes: "It had changed me. I might still not have reached home or settled where I belonged, but I was confident that there was home there, ahead of me. My homesickness wasn't cured but it was sure, propelling me in the right direction" (Aboulela 328). Natasha then perceives that her belonging and home do not necessarily connote a place or a territory, her home might be in something intangible. Thus, she seeks Malak's guidance and adjoins her in the spiritual journey to cure her feelings of loss due to her lack of belonging, and marginality and alienation from the dominant society of Britain. These feelings, thus, serve as stressors on Natasha that she is eager to overcome through an emotion-focused strategy. Accordingly, Natasha decides to accompany Malak in her spiritual journey. She explains: "I had come to her today needing to connect, wanting to spend time in her company. Perhaps it was time to acknowledge that what I was after was spiritual. She was ready to be a guide and I would fight my weaknesses in order to follow" (Aboulela 329). Malak and Natasha take up this spiritual approach seeking the same coping strategy - religious and emotion-focused coping - to soothe their acculturative stress. But especially for Natasha this spiritual journey is her opportunity to find her spiritual home and belonging that cures her perpetual sense of loss and lack of belonging.

To be capable of identifying the acculturation strategies that are sought by Natasha, Malak and $\mathrm{Oz}$ following the experience of acculturation stress, the correlation between stress coping strategies and acculturation strategies is utilized. With the identification of the stress coping strategies followed by Natasha, Malak and $\mathrm{Oz}$ after their experience of high acculturative stress, we can introduce the acculturation strategies they shift to through their reaction to and coping strategies with acculturative stress. In acculturation, the difference between attitudes and behaviors in acculturation strategies is presented by referring to attitudes as 'what an individual seeks' and behaviors as 'what he or she is actually able to do' (353). In this sense, the presentation of change in the acculturation strategy by Natasha, $\mathrm{Oz}$ and 
Malak following experiencing high acculturative stress and negative outcomes is manifested.

Apparently, the three characters of The Kindness of Enemies seek an emotion-focused coping strategy to cope with acculturative stress. By applying Kosic's perspectives in the relationship between coping strategies and acculturation strategies we deduce that Natasha, Oz and Malak's coping strategy directs them towards the separation acculturation strategy, especially with their conscious sense of alienation and marginality from the host society of Britain.

In comparison with their initial individual preferences as adopted acculturation strategies, it is evident that the three of them have changed their acculturation strategies in reaction to acculturative stress and to the aroused feelings of alienation and marginality. Natasha at first endorses an assimilation acculturation strategy, while Malak and $\mathrm{Oz}$ adopt an integration strategy. With the experience of high-level acculturative stress, they turn to a separation acculturation strategy that strengthens their relationship with their original culture or ethnic group - especially Islam - and distances them from the society of settlement. Apparently, the role of the majority group in this outcome is undeniable since the feelings of marginality and alienation experienced by Natasha, $\mathrm{Oz}$, and Malak means that they find themselves 'othered' or unaccepted by their society of settlement due to the conflict between Islam and the West. Consequently, adopting a separation acculturation strategy is not solely the characters' choice, but it is also welcomed by the Islamophobic British society.

\section{Conclusion:}

Leila Aboulela's The Kindness of Enemies presents the journey of three diasporic Muslim individuals within their long-term adaptation process. As Muslim immigrants in the West after 9/11, they individually adopt acculturation strategies to live in a different culture from that of origin. Natasha adopts an assimilation acculturation strategy through ditching her Muslim heritage and leading a Westernized life in Britain. On the other hand, Malak and $\mathrm{Oz}$ follow an integration acculturation strategy since both of them show idealization and loyalty to their origin, heritage, and religion along with their well-adjustment in the society of origin. Apparently, their choices of acculturation strategies depend mainly on their degree of attachment to their society of origin or birth as well as their connection to the society of settlement.

During their long-term adaptation process, Oz; Natasha; and Malak encounter a high-level acculturative stress due to their Muslim heritage and 
the existent Islamophobia among members of the dominant society. As a result of the stressors they encounter as suspected Muslims, the three characters experience high-level acculturative stress that leads them to negative emotional and psychological outcomes like, depression, alienation and marginalization.

Therefore, in reaction to their experience of high-level acculturation stress they adopt stress coping strategies to deal with stress and the sense of alienation and marginalization. Oz, Malak and Natasha follow an emotionfocused coping strategy. Oz follows this strategy by moving to another university away from his hometown. Malak decides to follow the emotionfocused coping strategy by the agency of religiosity and spirituality after being marginalized in her acting career. Finally, after suffering from acculturative stress, Natasha returns to her birth country, Sudan, and despite her sense of family with her brother Mekki and her slight feeling homesickness she realizes that her sense of loss and lack of belonging might not be in a place. Therefore, upon her return to Britain, Natasha joins Malak in her spiritual journey for her emotion-focused coping strategy to cure her sense of loss and lack of belonging as well as marginality and alienation in the country of settlement.

According to their adopted stress coping strategy and their common sense of marginality and alienation, the new acculturation strategy they direct to after acculturative stress is evident. Putting in consideration the correlation between stress coping strategies and acculturation strategies, apparently, the separation acculturation strategy is adopted by Natasha, Malak and, Oz and seems acceptable by the dominant society providing the alienation and marginality experienced by Natasha, Malak and $\mathrm{Oz}$ from the majority group of Britain. In conclusion, Natasha shifts her acculturation strategy from assimilation to separation, while Malak and $\mathrm{Oz}$ alter their firstly adopted integration strategy to a separation acculturation strategy, just like Natasha.

\section{Bibliography}

Adam, Zeenah and Ward, Colleen. "Stress, Religious Coping and Wellbeing in Acculturation Muslims." Journal of Muslim Mental Health 10.2 (2016): 3-25

Aihwa Ong, "Flexible Citizenship: The Cultural Logics of Transnationality." Durham: Duke University Press, 1999.

Alexander, M. The shock of arrival: Reflections on postcolonial experience. Boston: South End Press, 1996.

Almaeen, Mona. "Spirituality and Islamic Feminism: A Critical Analysis of Religious Agency in Selected Literary and Cinematic Works.” Diss. University of Kent, 2018. 
Berry, John W., Poortinga, Ype H., Segall Marshal H.\& Dasen, Pierre R. "Cross-cultural

Psychology: Research and Applications. " Cambridge University Press, 2000

----- "Acculturation as varieties of adaptation" (pp. 1-4) In A. Padilla (Ed.), Acculturation: Theory, Models and some new findings, Boulder, CO: Westview, 1980

----- W. J. W., Kim, U., Minde, T., \&Mok. D. “Comparative studies of acculturative stress.” International Migration Review, 1987

“Acculturation and adaptation.” In J. W. Berry, M. H. Seagull, \& C. Kagitcibasi (Eds.), Handbook of Cross-cultural psychology: Social behavior and applications (Vol. 3), Needham Heights, MA: Allyn and Bacon, 1997

----- "Immigration, Acculturation and Adaptation." Applied Psychology: An International Review, 1997

Bhatia, Sunil and Ram, Ajali. "Rethinking 'Acculturation' in Relation to Diasporic Cultures and Postcolonial Identities." S. Kager AG, Basel, 2001

Diaz, Criss Jones. "Diaspora, Hybridity and Growing up Bilingual in a Globalized World." Australian Association for Research in Education, 2005

Folkman, Susan and Richard S. Lazarus. "Coping as a Mediator of Emotion. ” Journal of Personality and Personal Psychology 54.3 (1988): 466-478.

Goforth, Anisa N.; Pham, Andy V.; Chun, Heejung; Castro-Olivio, Sara M.; and Yosai, Erin R. "Association of Acculturative Stress, Islamic Practices, and Internalizing Symptoms Among Arab American Adolescents." School Psychology Quarterly 31.2 (2016): 198-212

Kosic, Ankica. "Acculturation Strategies, coping process and acculturative stress." Scandinavian Journal of Psychology 45 (2004): 269-278

Stuart, Jaimee. “A qualitative analysis of Muslim young adults' adaptation experiences in New Zealand.” Journal of Muslim Mental Health, 2014

Tiwari, Roli; Singh, Bansh Gopal; and Basheer Hasan. "Acculturative Stress and Coping Strategies of foreign Students: A Systematic Review." Indian Journal of Health and Well-being 8.7 (2017): 683-687 